\title{
Development of coded emergency alarms through word-association tasks
}

\author{
NORMAN GRONER, JOHN P. KEATING, and ELIZABETH F. LOFTUS \\ University of Washington, Seattle, Washington 98195
}

\begin{abstract}
Information about a fire must be delivered to hospital personnel while being concealed from the patient population. Standard word-association procedures were used to develop the optimal coded message for such a situation. These procedures capitalized on connotation of words used in the code to communicate the situation to affected personnel.
\end{abstract}

When a fire occurs in a hospital, information about it must be communicated to appropriate personnel, while being concealed from the patient population. While some patients might be able to respond effectively, many of them are physically and/or psychologically unable to respond constructively. For example, recent burn victims, occupants of and visitors to intensive care units, and mentally disturbed patients are especially unpredictable in response to information that a fire is in progress in their building. Delivering information of the fire to them is likely to result in panic behavior.

Hospitals around the country respond to this problem by disguising the messages that communicate the existence and location of a fire. For example, in some of the hospitals, the message "code red, four west" alerts appropriate personnel that there is a fire on the fourth floor of the west wing.

Code red is but one of a variety of alerting messages used in different hospitals throughout the country to indicate a fire. Furthermore, hospitals vary the codes they use to indicate a cardiac arrest, a fire drill, a bomb threat, and other emergency situations. Because different codes are used in different institutions, and because the code itself invariably bears no relation to the concept it is used to indicate, alerting messages often cause confusion in the minds of those who hear them. Recently, during a typical fire drill at a major hospital a doctor was observed asking a nurse, "Is code red for fire or cardiac arrest?"

Confusion generated by various alert messages devoid of information could be lessened if alarm messages were standardized across hospitals, especially those in the same geographical vicinity, who commonly share medical personnel. It is essential that key personnel act swiftly and without panic to facilitate the safety of all involved in the emergency situation. Important time can

This research was supported by a grant from the HEWNBS Life/Safety Program under NBS Grant 6-9016. Requests for reprints should be sent to either John P. Keating or Elizabeth F. Loftus, Department of Psychology, University of Washington, Seattle, Washington 98195. be lost deciphering codes that are too abstruse, or codes that vary from one setting to another. To determine which code would be most effective, we applied some standard, relatively simple procedures common to experimental psychology. The purpose of this article is to report our methods and recommendation so that they might prove useful to other psychologists who seek to apply experimental psychology to the solution of important practical problems.

\section{EXPERIMENT 1}

Our goal was to develop a disguised message that would effectively present fire information to target recipients, enabling them to respond quickly. In this case target recipients are primarily nursing personnel, who are best prepared to deal with a fire emergency. We recommended that the title "nurse" be used to introduce the message, since not only are nurses the targeted recipients, but they are infrequently paged on hospital public address systems. To determine the precise code word, we used simple word-association procedures. We sought a code word that would elicit the response "fire" in a large proportion of the population; the code word would then be disguised by preceding it with the title "nurse," and announcing it as a surname.

\section{Pilot Study}

As a preliminary test to establish the methodology, we asked university students to give the first five responses that came to mind for each of three words. Two of the three stimulus words were irrelevant fillers, while the third was always the critical word. For 80 students the critical word was "smoke," while 80 others responded to "flames." We determined that "flames" was more strongly related to "fire" than was "smoke." To the word "flames," 75\% responded with the word "fire," with 58\% giving this as their first response. To the word "smoke," only $41 \%$ responded with "fire," with only $15 \%$ giving this as their first response. The final study then utilized the same wordassociation techniques, but extended the sample of words. 


\section{Full Study}

The subjects in this study included 241 individuals who participated in a study using methodology similar to that used in the pilot study. However, seven critical words were used: blaze, burn, flames, heat, red, spark, and torch. Approximately $1 / 7$ of the sample responded to each word. Table 1 indicates the percentage of subjects who responded with the word "fire" to each of the stimulus words. As can be seen, "blaze" and "flames" were the most highly related, eliciting the desired response from $91 \%$ and $78 \%$, respectively. The stimulus "red," which is commonly being used to announce a fire, was the least effective of the seven critical words, eliciting fire from only $11 \%$ of the respondents.

These data indicated that the code word "blaze" would be an optimal choice for a coded alarm, and that the message "Nurse Blaze" would effectively communicate fire information to hospital personnel. A final task was that of establishing the plausibility of "blaze" as a surname.

\section{EXPERIMENT 2}

Since the words "blaze" and "flames" were identified as most effective in eliciting the response "fire," these two words were examined for plausibility as a surname. Subjects were 72 individuals who were paid for their participation. They were presented with pairs of words, with each word preceded by the prefix "Mister," and their task was to indicate which name sounded more believable or more realistic to them. The critical pair was "Mr. Blaze/Mr. Flames," and this pair was judged along with five filler pairs. For the critical pair, $96 \%$
Table 1

"Fire" Responses to the Critical Words

\begin{tabular}{lcc}
\hline $\begin{array}{c}\text { Stimulus } \\
\text { Words }\end{array}$ & $\begin{array}{c}\text { Number of } \\
\text { Responses }\end{array}$ & $\begin{array}{c}\text { Percent Generating } \\
\text { "Fire" }\end{array}$ \\
\hline Blaze & 35 & 91 \\
Burn & 36 & 63 \\
Flames & 36 & 78 \\
Heat & 35 & 34 \\
Red & 35 & 11 \\
Spark & 31 & 71 \\
Torch & 33 & 73 \\
\hline
\end{tabular}

of the respondents found the name "Mr. Blaze" to be more plausible than "Mr. Flames." A simple addition of the physical location of the fire (e.g., four west) following the announced code completes the alarm message.

\section{DISCUSSION}

Using standard word-association techniques, an emergency alarm message for fire situations was empirically developed. The message, "Nurse Blaze, four west," could effectively communicate to appropriate hospital personnel the existence and location of a fire, while being disguised from the patient population. The word "blaze" is strongly related to "fire," and thus it is unlikely that this word would cause intended recipients to ask questions such as "Is Nurse Blaze for fire or cardiac arrest?" Furthermore, the word is plausible as a surname. With some confidence, we are recommending that this message be standardized throughout hospitals around the country to guarantee quick response by personnel in fire situations.

(Received for publication September 12, 1977.) 